\title{
Static Pressure Measurements of Enclosure Fires
}

\author{
B. J. McCaffrey and J. A. Rockett \\ Institute for Applied Technology, National Bureau of Standards, Washington, D.C. 20234
}

(July 5, 1977)

\begin{abstract}
Some enclosure-fire static pressure measurements are presented for both full and scale model rooms and are compared with the present hydraulics-orifice flow model for fire induced flows into and out of enclosures. Results indicate that the vertical pressure differential (enclosure to ambient) follows the expected hydrostatic distribution quite well and accurately reflects the doorway inflow and outflow gas velocities.

Measurement of ceiling and floor differential pressure using different numbers of gas burners yields insight into gross plume entrainment and illustrates how the neutral plane and thermal discontinuity vary with upper gas temperature. Correlating upper gas temperature with fire size and enclosure height makes it possible to predict at what heat release rate a given enclosure might become fully involved, i.e., by using the temperature at which the thermal discontinuity approaches the floor.

In terms of present fire plume modeling large entrainment coefficients $(0.3-0.4)$ are required in order to reproduce the enclosure flows for both the small and large scale results. A noted deficiency in the plume model appears in the small scale results where the data suggest that the entrainment should exhibit a much stronger dependence on the fuel injection rate than that predicted by the theory.
\end{abstract}

Key words: Buoyancy pressure; enclosure fires; entrainment; fire induced flows; models; physical scale; plumes.

\section{Nomenclature}

$A_{0}$

$C_{D}$

$c_{\boldsymbol{p}}$

D

$F r$

$g$

H

$H_{0}$

$k_{e}$

$\dot{m}$

N

$P$

$\Delta p$

$Q$

$r$

$T$

$\Delta T$

$u_{f}$

V

$W_{0}$

$W_{p}$

$W_{f}$

$y$

$y_{0}$

$z$

$\rho$

$\omega$ door opening area $\left(\mathrm{m}^{2}\right)$

orifice discharge coefficient

gas specific heat $(\mathrm{J} / \mathrm{kg} \cdot \mathrm{K})$

height of thermal discontinuity above floor $(\mathrm{m})$

plume Froude number $=u_{f}^{2} / g \cdot y_{0}$

gravitational acceleration $\left(9.8 \mathrm{~m} / \mathrm{s}^{2}\right)$

height of enclosure $(\mathrm{m})$

height of door opening $(\mathrm{m})$

entrainment coefficient

gas/air flow rate $(\mathrm{kg} / \mathrm{s})$

height of neutral plane above floor $(\mathrm{m})$

pressure (torr, $\mathrm{N} / \mathrm{m}^{2}$ )

pressure difference, enclosure to ambient $=\mathrm{P}-\mathrm{P}_{\mathrm{AMB}}$

(torr, also given as $\mathrm{N} / \mathrm{m}^{2}$ )

heat release rate $(\mathrm{kW})$

radial distance from plume axis

gas temperature $\left({ }^{\circ} \mathrm{C}, \mathrm{K}\right)$

temperature difference $\left({ }^{\circ} \mathrm{C}\right)$

gas burner flow velocity $(\mathrm{m} / \mathrm{s})$

gas/air velocity $(\mathrm{m} / \mathrm{s})$

door opening width $(\mathrm{m})$

entrained flow in plume $(\mathrm{kg} / \mathrm{s})$

gas burner flow rate $=\rho_{f} \pi y_{0}^{2} u_{f}$

height above floor $(\mathrm{m})$

radius of gas burner $(\mathrm{m})$

distance above or below neutral plane

gas density $\left(\mathrm{kg} / \mathrm{m}^{3}\right)$

fuel property defined by equation (9)

\section{Subscripts}

$\begin{array}{ll}\text { 0, Амв } & \text { Ambient properties } \\ \text { 0, OUT } & \text { outflowing gas } \\ i, \text { in } & \text { inflowing air } \\ f & \text { fuel }\end{array}$

\section{Introduction}

Present enclosure-fire modeling incorporates a hydraulicsorifice approach for calculation of the flow in and out of the opening $[1,2,3]{ }^{1}$ Due to the hot gases present in the upper portion of the room a pressure difference with respect to the ambient hydrostatic pressure is developed across the opening which is responsible for driving the flow. The gas in the room is assumed stationary and the flow rate is determined using Bernoulli's equation with an appropriate orifice coefficient. Additionally the gas flow in and out of the enclosure is coupled via entrainment of the fire plume. Figures 1 and 2 illustrate these ideas schematically. A step function for temperature with the thermal discontinuity being $D$ meters above the floor is commonly assumed and used since it leads to integrals expressible in closed form. However, any temperature distribution can be handled by direct numerical integration. The ambient pressure is simply hydrostatic, i.e., $-\rho_{0} g y$, and the enclosure pressure is made up of two pieces one above and one below $D$ as indicated. The upper portion is hydrostatic but with a different slope, $-\rho g y$, and must intersect the ambient at $N$, the neutral plane height. $N$ demarks the interface between the incoming and the outgoing gas, i.e., $v=0$. The upper portion is continued down to $D$ after which the slope must abruptly change to accommodate the ambient density. The driving force is the difference between the enclosure and the ambient pressure and is shown as $\Delta p$ in figure 2 together with an idealized velocity profile at the exit. In reality the flow field will be more complex near the door with entrainment and possible recirculation occurring near the shear region.

Enclosure models incorporating the above hydraulic scheme have been reasonably successful as regards gross features of the burning behavior of compartments [2]. However, the weaker areas where more work is required will be

'Figures in brackets indicate the literature references at the end of this paper. 


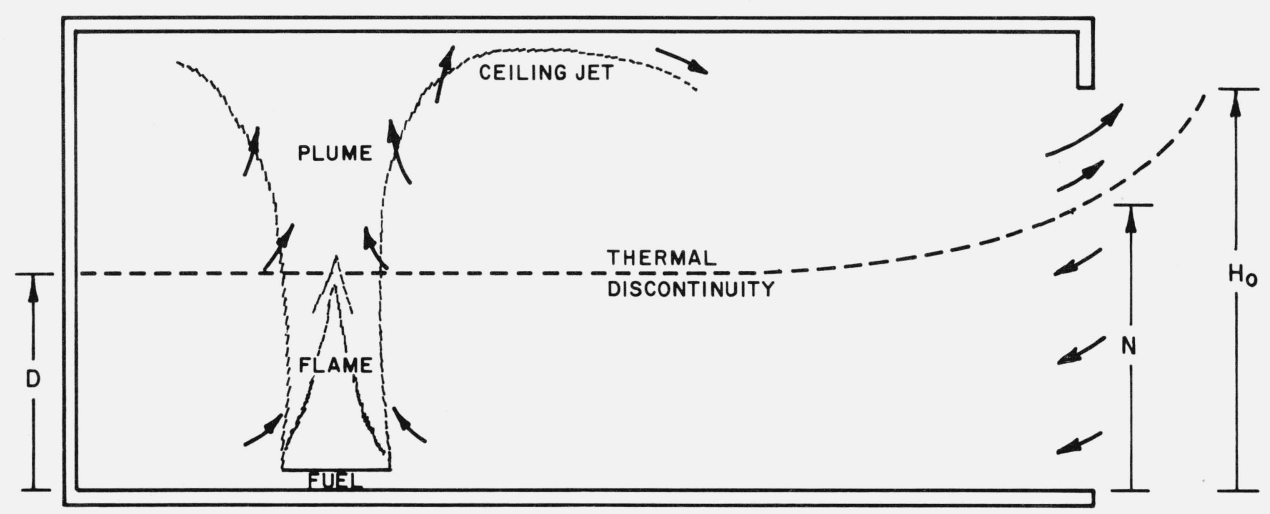

FigURE 1. Room geometry.

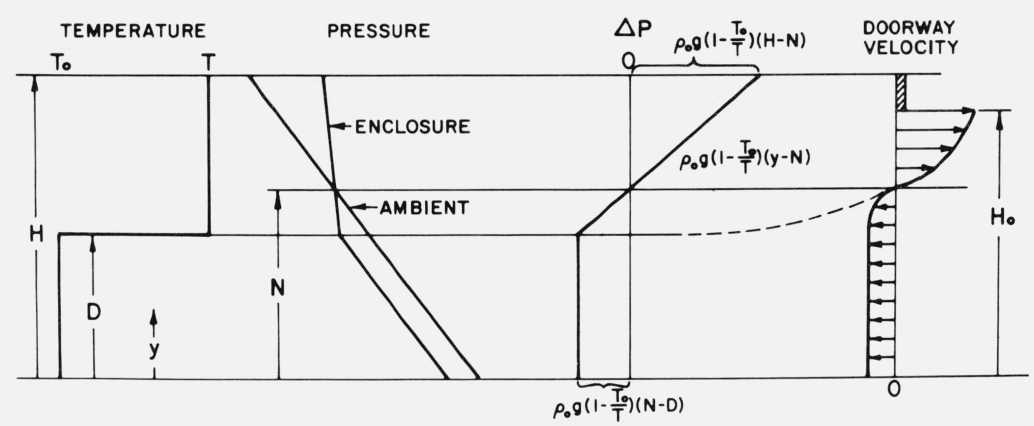

FIGURE 2. Plots, using a common height scale, to show the interrelation of temperature, pressure difference and door flow.

difficult to identify until the validity of the flow portion of the model is determined. Recent experimental work using salt water-fresh water analogs [3] may not be valid for sizeable fires due to the limited density ratios available. Presented here are some measurements of $\Delta p$ in full-scale and scale model enclosure burns. Shown will be both vertical distributions of $\Delta p$ and $\Delta p$ as a function of temperature for a given height. The latter measurements can be used as a guide in assessing the other piece of enclosure modeling, that is, plume entrainment which determines the height of the thermal discontinuity.

\section{Experimental Apparatus and Procedures}

\subsection{Full-Scale}

Complete details of the full-scale experimental facility are contained in reference [4]. The enclosure dimensions were $3.0 \times 3.0 \times 2.3 \mathrm{~m}$ high with a $0.73-\mathrm{m} \times 1.93-\mathrm{m}$ high doorway offset to one side; a moveable gas burner provided the fire source. Static pressure taps were made by inserting copper tubing through the wall from the outside and positioning them just flush with the inside surface. Type K $(0.25$ $\mathrm{mm}$ D), unshielded and unaspirated, thermocouples deter- mined the temperature at the pressure measuring positions. No radiation corrections were made; the implications of this are discussed in the text. Other tests at NBS, still in progress and not reported here, show that radiation can be quite important to room fire thermocouple readings. The differential pressure transducer was located on the floor with one pressure tap positioned outside of the burn-room and away from the door inflow and shielded from large drafts. The pressure signal at each height then was the difference between the room and the ambient pressures at that height. The pressure taps were located in the doorwall corner except where noted. Pressures were measured with a variable capacitance electrical manometer calibrated against a micromanometer water column which can be read fairly accurately to $10^{-1} \mathrm{~N} / \mathrm{m}^{2}$.

For the smaller fires, the burner, located $0.30 \mathrm{~m}$ above the floor, was usually run for a period of ten minutes, the duration of the test; for larger fires the corresponding running time was shorter. Due to the highly insulated ceiling and walls, a quasi-steady condition was reached quickly.

\subsection{Model}

Measurements of $\Delta p$ across the doorway at the floor and ceiling of a scale model burn-room were made during the 
steady operation of up to three Meeker gas burners used for fire simulation. The room was $0.39 \mathrm{~m}$ wide by $0.37 \mathrm{~m}$ deep by $0.41 \mathrm{~m}$ high with a $0.11 \mathrm{~m}$ by $0.29 \mathrm{~m}$ high doorway opening located symmetrically in the $0.39 \mathrm{~m}$ wall. The facility was the same as that used in a recent burn-room corridor study [5] except that the corridor was open at both ends allowing the burn-room to interact with the ambient air without the additional complexity introduced by a corridor. The burners were located $0.055 \mathrm{~m}$ above the floor (except where noted) and arranged in an approximately triangular fashion around the room. They were separated sufficiently so as to eliminate plume merging. The pressure taps were implanted similar to the full-scale procedure. Upper gas temperature was monitored in the rear of the box at a position on the centerline $0.37 \mathrm{~m}$ high and $0.04 \mathrm{~m}$ out from the wall. Observations of other thermocouples in the upper portion of the box indicated that the gases were well stirred.

\section{Results and Discussion}

\subsection{Full-Scale}

Figure 3 shows a typical vertical pressure traverse with the burner located in the center of the room for two nominally identical runs of $140 \mathrm{~kW}$ fires. The circles indicate readings with the pressure and temperature taps in the usual doorwall corner, and the squares show values taken at an interior corner in order to gage any variation due to location of the measuring station. The slight differences noted are probably more indicative of the fact that the second run (squares) was made immediately after the first, without waiting for the room to cool, as opposed to a true room non-uniformity. In figure 4 values of temperature are shown for both the interior at the pressure taps and for the doorway [4]. No radiation correction was made. Note that the interior values approximate the doorway results. Note also that some mixing of the hot gas with the incoming air has occurred. Ambient air is at $23.5{ }^{\circ} \mathrm{C}$ yet the "door" flow indicated temperature is 39 ${ }^{\circ} \mathrm{C}$ and the lower gas deep in the room is $56{ }^{\circ} \mathrm{C}$. These temperature readings could occur for several reasons of which the more obvious include possible mixing of heated air from the room with the incoming air or an error of the thermocouple reading due to radiation from the flame, hot upper gas and upper wall and ceiling surfaces. If it is assumed that radiation has raised both these temperatures $39-23.5=15.5^{\circ} \mathrm{C}$, then the true deep room temperature, below the hot layer, would be about $40.5^{\circ} \mathrm{C}$.

The slope of the line drawn through the upper pressure points in figure 3 was determined using an average upper gas temperature of $219^{\circ} \mathrm{C}$ and the hydrostatic relation,

$$
\Delta p=\rho_{0} g\left(1-\frac{T_{0}}{T}\right)(y-N) .
$$

Alternately if one measures $\Delta p$ and $T$ at any height, $y$, then the neutral plane height, $N$ can be determined. The agreement between the line and the upper three points shows clearly the hydrostatic nature of the differential pressure across the door. Only the upper three points were used since further down the temperature begins to fall dramatically and the simple two layer temperature expression, i.e., eq (1) will no longer hold. In general, however, as the temperature drops the $\Delta p / H$ slope will decrease and this is evident on

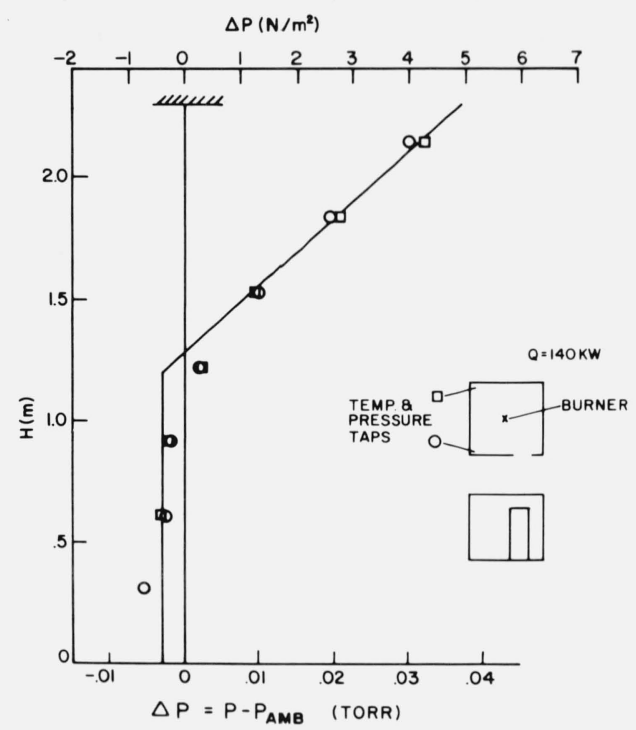

FiguRE 3. Vertical differential pressure for two-measurement positions.

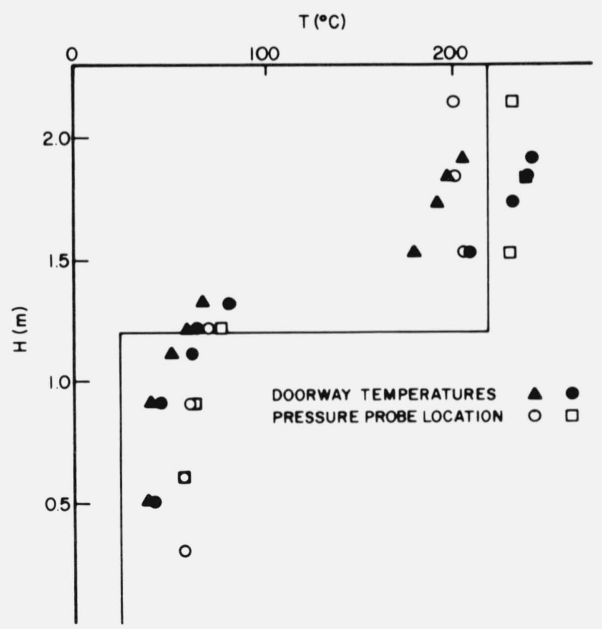

Figure 4. Vertical temperature distributions, measurements made at the two interior pressure tap locations shown in figure 3 and in the doorway for two tests.

the pressure plot in the regime between the third and fourth data points down from the ceiling. The upper three points yield a predicted neutral plane, $N$ of $1.3 \mathrm{~m}$ or approximately +18 percent higher than the actual, interpolated value of $1.1 \mathrm{~m}$.

The pressure differential in the lower half of the room for the model of figure 2 is given by the expression,

$$
|\Delta p|=\rho_{0} g\left(1-\frac{T_{0}}{T}\right)|(N-D)| .
$$


An average value of $\Delta p$ for the three sets of lower points $\left(-0.0029\right.$ torr, $\left.-0.39 \mathrm{~N} / \mathrm{m}^{2}\right)$ together with the average upper gas temperature $\left(219^{\circ} \mathrm{C}\right)$ will determine the thermal discontinuity or $N-D=0.08 \mathrm{~m}$. The vertical line shown going through the average $\Delta p$ rises to $D=1.22 \mathrm{~m}$, using the predicted $N$, where it meets the predicted upper hydrostatic line. The horizontal or temperature-break portion of figure 4 showing $D$ is somewhat lower than the actual break one might choose from the data. If it turns out that the enclosure pressure distribution is representative of the doorway flow then figures 3 and 4 indicate that cold air is being swept out the door.

In reference [1], Rockett states that the thermal discontinuity deep in the room must be below the neutral plan. Comparison of figures 3 and 4 show that this is obviously not true. As will be shown below, this "anomaly" arises from the assumption by Rockett [1] that the lower gas temperature is ambient. If the incoming air is heated, there is no need for the "major" thermal discontinuity to be below the neutral plane.

The other obvious discrepancy with the simple hydrostatic flow model concerns the nonuniform lower pressure distribution. There is a tendency for $|\Delta p|$ to increase as the floor is approached, and this should be evident in the doorway velocity profile, with higher flows closer to the floor. In the interior the cold temperature is also measurably greater than a representative ambient temperature. The fact that the door is not symmetrically located with respect to the room and burner may be partially responsible for the anomalies. An additional swirl due to turning of both the in and out flows superimposed on the flow field might lead to an increased mixing across the supposedly stable thermal discontinuity.

How well the data compares with a hydrostatic pressure variation and an arbitrary temperature distribution can be seen in figure 5 where average pressures and temperatures (interior) from figures 3 and 4 are displayed. The hydrostatic pressure difference, interior minus exterior, referenced to the neutral plane and assuming an ideal gas is given by

$$
\Delta p(z)=g \rho_{0}\left[z-T_{0} \int_{0}^{z} \frac{1}{T(z)} d z\right]
$$

where $z$ is measured above or below the neutral plane. The temperature points on figure 5 were joined by straight lines. The integral in eq (3) was evaluated with the "trapozoidal rule" to determine $\Delta p$. Due to the sharp temperature discontinuity, the use of higher order polynomial curve fits are generally unsatisfactory. The neutral plane was specified from the actual pressure data.

In carrying out the numerical integration the temperatures uncorrected for radiation were used. Had these data been approximately corrected by substracting $16{ }^{\circ} \mathrm{C}$ for values below the (radiating) hot layer, the pressure would have increased less rapidly with height than the measured values. Conversely, if the lower three pressures are used to establish a temperature, $47.8{ }^{\circ} \mathrm{C}$ is obtained. This suggests a radiation correction closer to $8{ }^{\circ} \mathrm{C}$ than $16{ }^{\circ} \mathrm{C}$.

Also shown on figure 5 is the two-temperature model, based on a single upper gas temperature and ambient lower temperature. This model yields a slope dependent on temperature for the pressure in the upper part of the room and a vertical line for the differential pressure in the lower part of the room. In the case shown here the upper three points were used to locate the derived pressure profile for the upper portion and the average of the lower pressures to fix the vertical line. Their intersection gives the neutral plane as opposed to using the measured neutral plane as was done for the numerical integration plot. By using the derived slope for the lower points i.e., $T=59^{\circ} \mathrm{C}$ approximately as opposed to ambient, an alternate gas model could be sketched onto the figure. This alternate model would appear as a line going through the lower pressure points with the same slope as the integrated plot and intersecting the upper hydrostatic line somewhere above the neutral plane. $D$ would then be above $N$ as the data indicates. Obviously many combinations exist. Temperature data or a two-temperature approximation can only yield the shape of the pressure profile; an additional relation is needed to specify the location of the profile. This is usually accomplished theoretically by coupling the fire plume entrainment flow up to the thermal discontinuity with the gas flowing out the door [1, 2].

Whether one chooses a two-temperature model or the numerical integration of temperature data, figure 5 indicates clearly the hydrostatic nature of the vertical pressure distri-

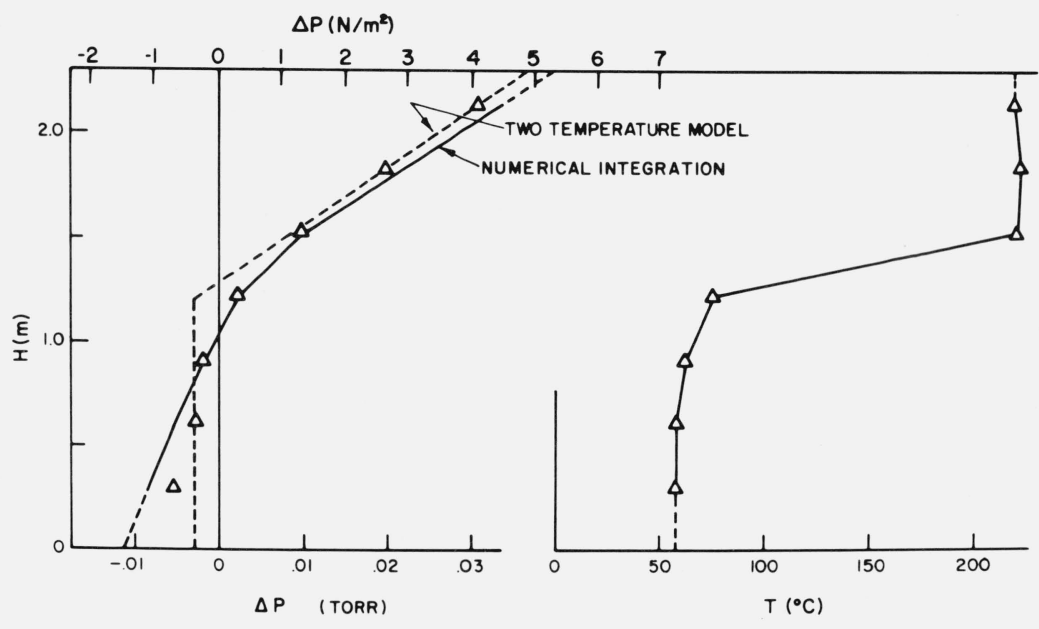

Figure 5. Hydrostatic pressure models. 
bution. That aspect of the flow model therefore appears sound. It is left to determine how well the interior pressure reflects the doorway flow.

The variation of pressure and temperature due to the location of the fire within the enclosure is shown in figure 6 . Data for three positions of the burner: the center of the room, the middle of the rear wall, and a rear corner, are presented for one size fire, $140 \mathrm{~kW}$. Upper gas temperatures are significanly hotter for the corner burner configuration as compared to the center. Additionally, the observed thermal discontinuity, as well as a predicted neutral height, will be higher than those corresponding to the center burner configuration.

An argument based on plume entrainment could be forwarded to explain these results. The center burner being completely unrestricted is able to entrain more cold air and hence yields cooler upper gas temperatures than the corner burner which is inhibited on the two sides of the corner. Also, less entrainment will result in a higher neutral plane. It should be pointed out that the burner was square shaped and was positioned flush with the walls for the corner and wall positions.

The effect of fire size on pressure and temperature for a given burner location, the corner, is shown on figure 7 . In this figure pressure slopes were derived from the average upper gas temperature and drawn down through the top most measured pressure. As would be expected, bigger fires produce higher temperatures and larger differential pressures. Finding the slope of the pressure-height relation, using the data on figure 7 and eq (1), will result in a quite small variation in predicted neutral heights for the four cases, i.e., 1.3 to $1.5 \mathrm{~m}$ above the floor with $N$ decreasing with increasing temperature (straight lines on fig. 7). As was seen in figure 3 , the predicted $N$ also lies well above the measured values for the cases where data is available.
Having established the hydrostatic nature of the vertical pressure variation within the enclosure it is now left to determine how well this distribution reflects the doorway flow field. Figure 8 is a plot of the measured centerline velocity in the doorway [4], shown by the lines, as against a velocity calculated from the pressure measurements of figure 6 , shown by the symbols. Here velocity is defined as $(2 \Delta p /$ $\rho)^{1 / 2}$ where $\rho$ is calculated using air at the local temperature. It can be seen that the interior pressure measurements represent the doorway character exceedingly well; not only is the magnitude of the static pressure calculation the right order, but the position of the interpolated neutral plane is identical to the position of the measured velocity reversal.

In the hydraulics model the velocity $(2 \Delta p / \rho)^{1 / 2}$ is used together with the area and local density to determine the gas flow rate which is then multiplied by an orifice or discharge coefficient, thought to be equal to about 0.68 . Multiplying the pressure calculated values by 0.68 on figure 8 would result in better agreement with the measured velocities for the incoming flow. However, for the outgoing gases this procedure would not improve the agreement. A more detailed evaluation, including off-centerline velocity traverses and truly steady-state conditions, could yield the accuracy required for evaluation of the discharge coefficient in a real fire situation.

Using the pressure and temperature data, the mass flow rate in and out the door can be determined by assuming uniform flow across the door width. Forming $(\Delta p / T)^{1 / 2}$, plotting it versus height, finding the area under the curves, multiplying by an appropriate constant, and arbitrarily cutting off the outflow at the soffit height will yield the flow rates. For the center burner position shown in figure 8 the resulting mass balance is within 12 percent with $\dot{m}_{\text {out }}=$ $0.82 \mathrm{~kg} / \mathrm{s}$ and $\dot{m}_{\text {in }}=0.72 \mathrm{~kg} / \mathrm{s}$. (For fully involved enclosures $\dot{m} \approx 0.5 A_{0} \sqrt{H_{0}}=0.5 \times 1.41 \times \sqrt{1.93}=0.979 \mathrm{~kg} /$

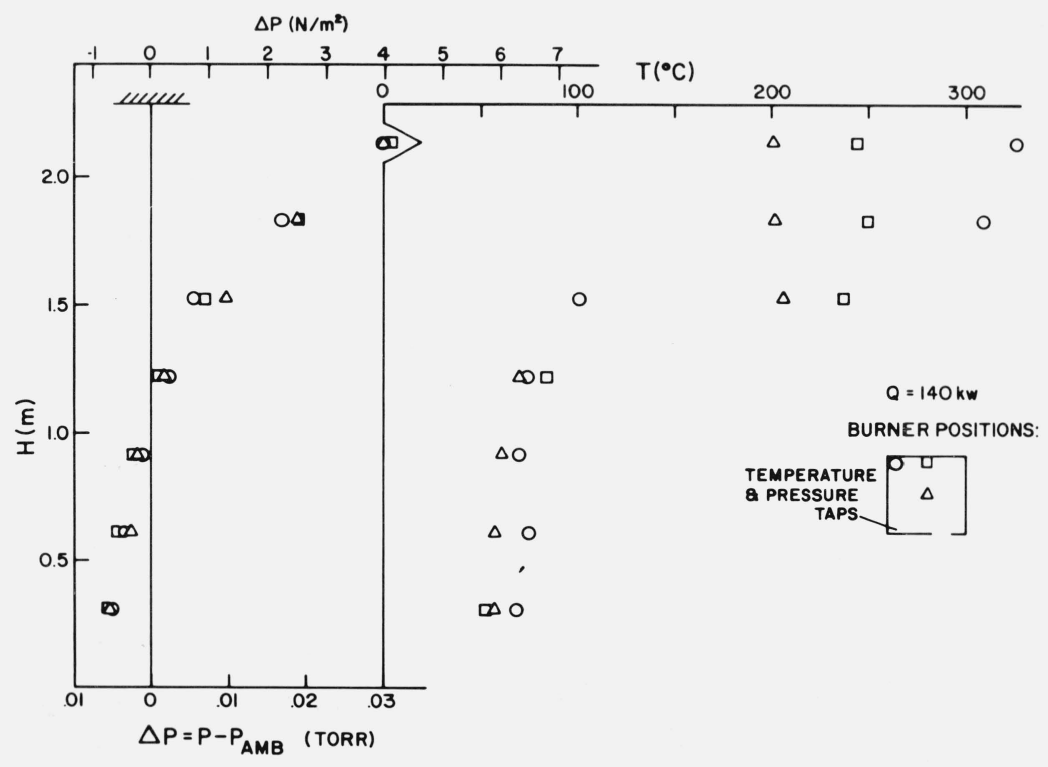

FIGURE 6. Vertical pressure and temperature distributions for various fire locations. 


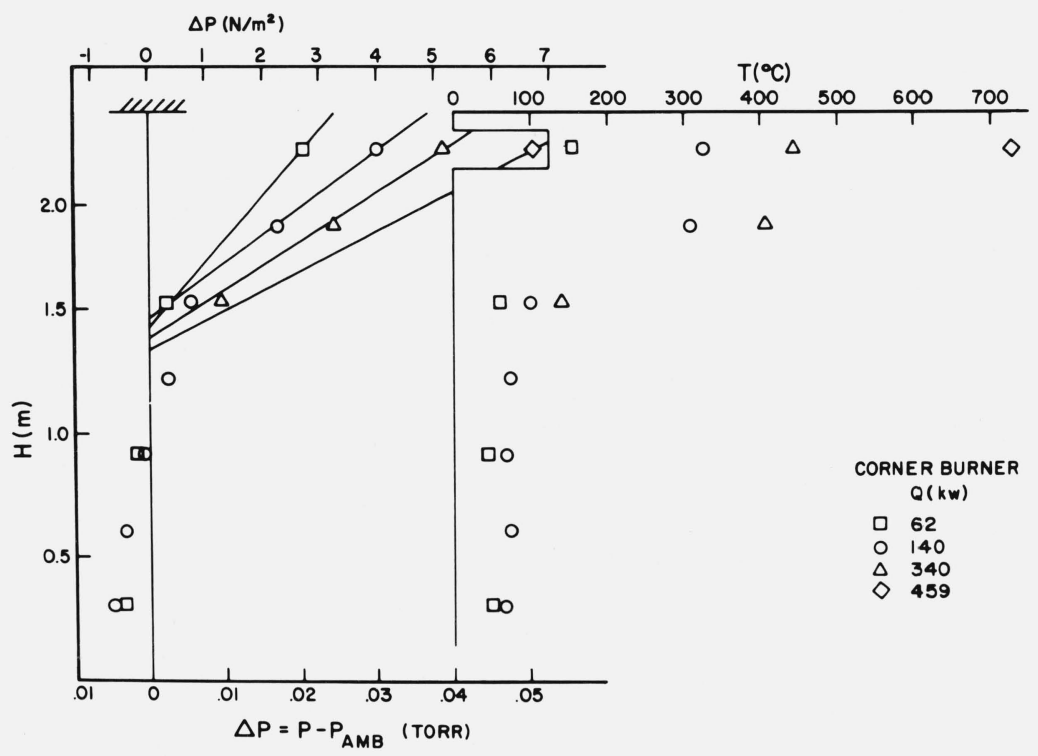

FiguRE 7. Vertical pressure and temperature distributions for different fire sizes.

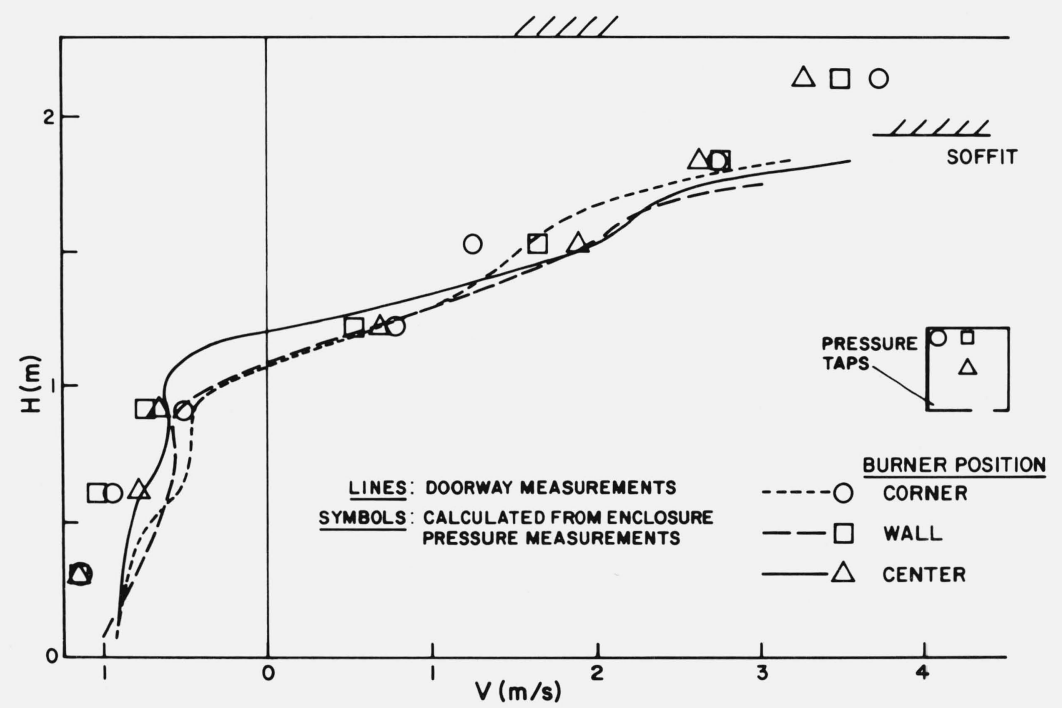

Figure 8. Comparison of doorway velocity measurements with static pressure calculation.

s). Around 10-15 percent is probably as good a balance as can be expected without going to extraordinary measures. The amount of $\mathrm{CH}_{4}$ required for the size fire used is approximately $0.0025 \mathrm{~kg} / \mathrm{s}$ which will not appreciably change the balance. Since only $0.044 \mathrm{~kg} / \mathrm{s}$ air is required for complete combustion of this amount of methane, about 17 times more air is flowing through the enclosure than needed for combustion.

\subsection{Small Scale}

The pressure drop across the doorway at the ceiling and floor was measured for a series of fire sizes and different combinations of burners in the scale model burn-room.
Specifically, runs were made using three burners, two burners and one burner with their normal diffusing cones in place. These allowed the gases to exit $0.055 \mathrm{~m}$ above the floor. Additionally the diffusing cone was removed from one burner and a series of experiments was run with the flames issuing from the floor through a small exit. Different numbers of burners with different heights and areas should entrain differently and the flow or $\Delta p$ should be thus effected.

Figure 9 represents $\Delta p$, normalized to doorway opening, at the ceiling and floor for the above burner combinations plotted against a representative upper gas temperature. Also shown are the previous full-scale results from figures 6 and 7. These are scaled up from $2.13 \mathrm{~m}$, the highest measuring point, to the ceiling via a slope determined from the actual 
temperature measurement, through eq (1). Additionally, a least squares fit of the data of reference [6] is shown by the solid line. ${ }^{2}$ This work involved the burning of various size sheets of polymethylmethacrylate in a small scale enclosure $(0.30 \times 0.30 \times 0.56 \mathrm{~m}$ deep $)$ with various size door openings. The pressure at the ceiling was recorded during the steady burning period and the line shown in figure 9 represents 33 experiments extending from low temperature $\left(<450{ }^{\circ} \mathrm{C}\right)$ plume-like burning (small sheets/wide openings) to a condition in which flames occupied nearly the entire volume, spilling out the door and with temperatures from $700{ }^{\circ} \mathrm{C}$ to $1100^{\circ} \mathrm{C}$ (large sheets/small openings).

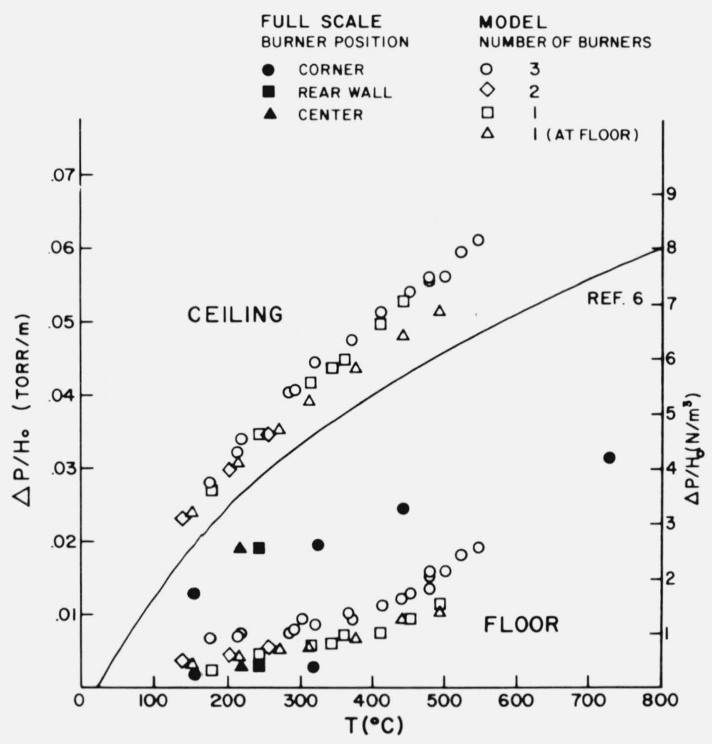

FIGURE 9. Ceiling and floor differential pressure versus upper gas temperature.

As is clearly indicated in figure 9 there is considerable disagreement between the full-scale results and both small scale results. In the previous section it was determined that the measured pressure overestimates the neutral plane height by 18 percent. If $N$ is reduced by 18 percent the pressure will increase somewhat but the disagreement will still be substantial. Note that in general as the number of burners is reduced in the small scale and the position of the burner is set to the floor incorporating a smaller exit (due to removing the diffuser cap to lower the burner), the neutral plane height will increase and $\Delta p$ decrease thus the results will tend toward those of full-scale. In any event, it is clear that the $\Delta p$ is smaller in the full-scale than in the model and, with our instrumentation, this difference cannot be attributed

${ }^{2}$ Equation 1 for $y=H$ is written in the form

$$
\frac{\Delta p}{\rho_{\mathrm{og} H} H\left(1-\frac{T_{0}}{T}\right)}=1-\frac{N(T)}{H} .
$$

The least squares fit then uses the experimental $N(T)$ to determine the coefficient of an assumed linear relation for $N(T)=N_{0}+N^{\prime} T$. to exinerimental error. The reason for this is not known; we can speculate, however, about possible reasons. Since both effects reduce entrainment to a first approximation it can be tentatively concluded that small scale fires tend to entrain more than the corresponding full-scale fire, or at least some effect causing larger $\Delta p$ 's is present in small scale.

Different netural heights for the different burner configurations is explicitly shown in figure 10 together with the calculated thermal discontinuities both normalized to the opening height and both displayed as a function of temperature. $N / H_{0}$ is calculated solely from eq (1) using the measured ceiling $\Delta p$ and $T . D / H_{0}$ requires both the floor and ceiling measurement of $\Delta p$ and utilizes both equation 2 for $D$ and eq (1) for $N$. Here it is being assumed that the twotemperature model is sufficiently representative. Also displayed are the least squares results from reference [6] and the previous large scale results reduced by 18 percent in order to produce a more realistic picture of the actual neutral plane location. Note that the discrepancy between large and small scale is now less dramatic and in fact the large scale center burner (darkened triangle; most entrainment of large scale) neutral plane is practically coincident with that of the small scale one burner at the floor case (opened triangle; least entrainment of small scale).

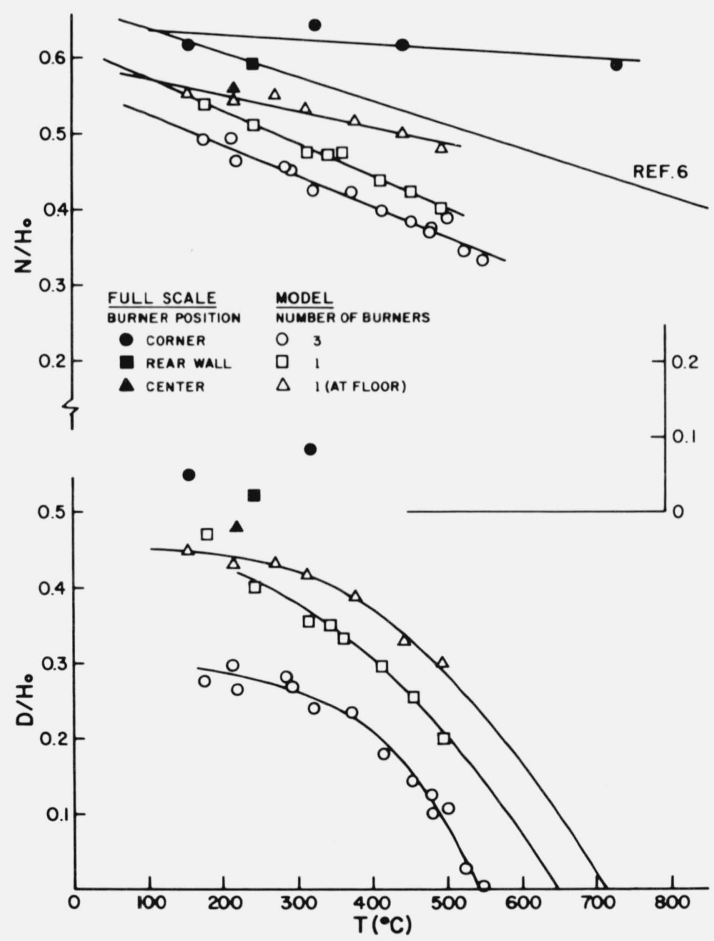

FIGURE 10. Calculated values of neutral plane and thermal discontinuity height normalized to door height.

As already stated, figure 10 was prepared using pressure data and eq (1) to calculate $N$. For the model test, door flows were not measured so $N$ could only be obtained by calculation. For the full-scale tests the pressure data were used in the same way, for consistency, but in this case door 
flows were measured and experimental neutral heights are available for 4 of the 6 (solid) points plotted on figure 10 . These 4 values of $N$, if plotted, would all lie below the reference [6] result and above the 1 burner (open squares) result. The lines shown are linear least squares fit of the data and the slope for the small scale results decreases in going from the three burner (opened circles) most entrainment case to the one burner at the floor (opened triangles) least entrainment case. Based on the above, a representative neutral plane versus upper gas temperature relation for a typical room, i.e., one with a "normal" door, would fall somewhere around the lines representing the data of reference [6] and those of the open triangles. In general door width is another important parameter which must also be considered [5].

The effect of entrainment is even more evident in the thermal discontinuity relation. On figure 10 the lines on the $D / H_{0}$ portion are fair representations of the data with some extrapolation. The implication of this figure is significant. It is well established experimentally that the air flowing in and out of the compartment for fully involved fires will tend toward a maximum. This is the so called "flashed over" room or ventilation controlled fire. In modeling, this maximum flow condition is obtained by allowing the thermal discontinuity, $D$, to approach zero. By inspection of eq (2) the pressure drop in the lower part of the room (or inflow) maximizes as $D$ approaches zero for fixed $T$ and $N$. Therefore, how $D$ drops with increasing temperature will be important in predicting flashover. The significant differences noted in the figure are postulated to be due to different entrainment, and hence the importance of the character of the fire or plume cannot be overstressed. Using the extrapolated lines a difference of $150{ }^{\circ} \mathrm{C}$ from about $550{ }^{\circ} \mathrm{C}$ to $700{ }^{\circ} \mathrm{C}$ results for the two small scale cases previously discussed. It is interesting to note that in reference [6], where the fuel consisted of a single sheet of PMMA burning near the floor, the fully involved fires were all grouped at temperatures of $700{ }^{\circ} \mathrm{C}$ and beyond. The data grouped into two regimes, points below $450{ }^{\circ} \mathrm{C}$ and those above $700{ }^{\circ} \mathrm{C}$ with none in between. From the standpoint of figure 10 a room fire consisting of more than one discreet plume would appear to be more dangerous than a single plume of the same total heat release rate. Obviously, however, radiation consideration and possible ceiling impingement from a single larger plume may well invalidate this conclusion.

Also shown on the $D / H_{0}$ portion of figure 10 are full-scale results using the pressure measurement at $0.305 \mathrm{~m}$ above the floor as was done for figure 9. Since the pressure difference appears to be getting larger as one approaches the floor these results probably indicate a higher thermal discontinuity than one which would result if the pressure was measured at the floor. Note the center burner point is not too different from the small scale single burner at the floor results, but obviously more full-scale data is required before definite conclusions can be drawn. Here again, the fullscale data were treated consistently with the model data. If the additional experimental data available for 4 of the 6 the full-scale tests were used, all four full scale points would fall lower in the plot, most noticeable the point at $320{ }^{\circ} \mathrm{C}$. They would scatter around the open triangles.

Having derived both neutral plane and thermal discontinuity heights from independent measurements of the ceiling and floor differential pressure it would be interesting to compare the derived inflow and outflow using the two temperature hydrostatic model. All that is required is $N, D$ and the upper gas temperature, $T$. From reference [2] the outflow is:

$$
\dot{m}_{0}=\frac{2}{3} C_{D} W_{0} H_{0}^{3 / 2} \rho_{0} \sqrt{2 g \frac{T_{0}}{T}\left(1-\frac{T_{0}}{T}\right)}\left(1-\frac{N}{H_{0}}\right)^{3 / 2}
$$

and the inflow

$$
\begin{aligned}
\dot{m}_{i}=\frac{2}{3} C_{D} W_{0} H_{0}^{3 / 2} \rho_{0} \sqrt{2 g\left(1-\frac{T_{0}}{T}\right)\left(\frac{N}{H_{0}}-\frac{D}{H_{0}}\right)} & \\
& \left(\frac{N}{H_{0}}+\frac{D}{2 H_{0}}\right)
\end{aligned}
$$

where $C_{D}$ is the orifice coefficient, here taken as 0.68 . Figure 11 is a plot of the mass flows in and out normalized by the ventilation parameter, $W_{0} H_{0}^{3 / 2}$. The simple modeling prediction [1] for $\dot{m} / A_{0} \sqrt{ } H_{0}$ is about 0.4 to $0.6 \mathrm{~kg} \mathrm{~s}^{-1} \mathrm{~m}^{-5 / 2}$ for $D=0$. The symbols give the average of the flow in and out and the error bars indicate the extremities of the two flows. For both sets of data where the burners were raised above the floor, computed outflow exceeds inflow and it does so significantly, especially at higher temperatures. Higher outflow versus inflow results from a low value of $N$ irrespective of $D$. The excess mass is generally greater in the three burner case, which is consistent with figure 10 . For the case where the burner is located at the floor, the inferred inflow is greater than outflow. Here the opposite condition is true, $N$ is larger. This lack of mass balance is a weakness of the present model. Note the behavior of the three burner case as $T$ approaches $550{ }^{\circ} \mathrm{C}$-the average mass flow rate ceases to increase even through the outflow appears to be consistently increasing with $T$ and the inflow consistently decreasing.

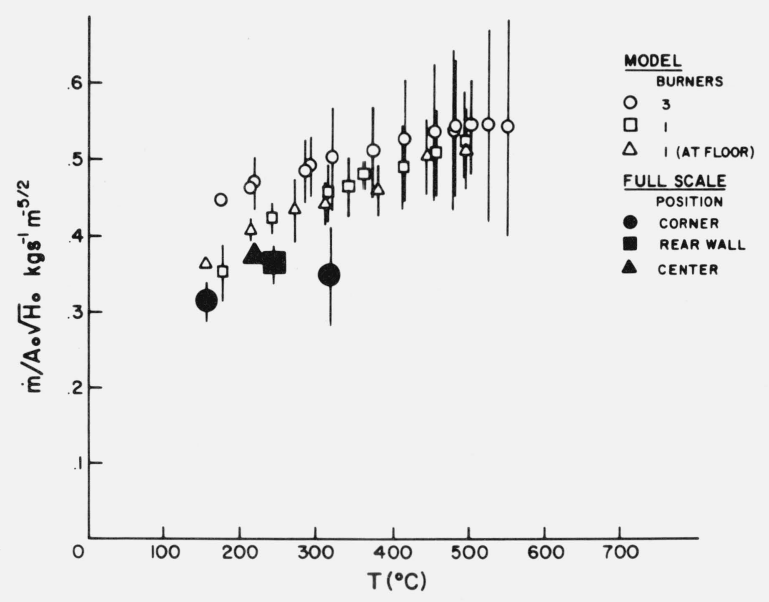

FigURE 11. Mass flow rates versus upper gas temperature.

Also shown are full-scale results (darkened symbols) which again fall below those of small scale and exhibit greater inflow than outflow (high $N$ ). In comparing large and small scale there is nothing new in this plot. Small scale is yielding higher $\Delta p$ 's and therefore lower $N$ and $D$ and thus more flow. The full-scale center burner result (large triangle) is once again approaching that of the small scale, single 
burner at the floor results (small triangles). Had the experimental $N$ 's been used rather than calculated $N$ 's the calculated full-scale flows would be larger. The value of $\dot{m} / A_{0} \sqrt{ } H_{0}$ is $0.373 \mathrm{~kg} \mathrm{~s}^{-1} \mathrm{~m}^{-5 / 2}$ for both inflow and outflow or $\dot{m}=$ $0.73 \mathrm{~kg} / \mathrm{s}$ which compares favorably to the values measured directly from the vertical pressure distribution on fig. 8, i.e., $\dot{m}_{0}=0.82, \dot{m}_{i}=0.72 \mathrm{~kg} / \mathrm{s}$. Recall however that these values were not multiplied by a discharge coefficient.

Since most of the previous parameters are expressed as functions of upper gas temperature it would be convenient to be able to relate temperature with the burning rate of the fuel and the size of the compartment. A completely analytical expression incorporating type, size and position of the fuel array, type of wall material, ventilation, etc. is beyond the scope of the present work. There is available however, sufficient data to obtain some phenomenological relations between the various variables.

From plume theory, correlations exist relating fire size, temperatures and height above the plume source. For an isolated ceiling (no walls), the temperature rise is given as [7]

$$
\frac{\Delta T}{Q^{2 / 3} H^{-5 / 3}}\left(\frac{c_{p}^{2} \rho_{0}^{2} g}{T_{0}}\right)^{1 / 3}=f\left(\frac{r}{H}\right)
$$

where $r$ is the radial distance away from the axis of the plume. It might be expected that for an enclosure the stirred upper gas temperature might also scale with the product $Q^{2 / 3} H^{-5 / 3}$ where $H$ is the enclosure height. Figure 12 shows the present data as well as additional full-scale burner simulation results from reference [8]. In general the small scale results are at a slightly higher temperature than those of full-scale. Note that these results are for the preflashover regime i.e. temperatures below about $500{ }^{\circ} \mathrm{C}$. The one fullscale point at $700{ }^{\circ} \mathrm{C}$ is not expected to fall with the lower temperature points based on the results of reference [6]. In that work no correlation appeared to exist for the high temperature, complete flame- over, runs while all the low temperature results correlated very nicely with the empirical relation mass loss rate to the two-thirds power multiplied by a ventilation parameter or width factor to the minus onethird power. Ventilation was not included as a parameter for the results on figure 12 since geometrically the door widths were approximately all scaled similiarly.

A straight line through the data of figure 12 yields the constant for the right-hand side of equation 6 equal to 13 with most of the scatter within \pm 15 percent. Note that a slope of a line through the full-scale data is $\Delta T / Q^{2 / 3} H^{-5 / 3}=$ $34 \pm 5 \mathrm{~K} / \mathrm{kW}^{2 / 3} \mathrm{~m}^{-5 / 3}$. Since $\left(c_{p}^{2} \rho_{0}^{2} g / T_{0}\right)^{1 / 3}=0.380$, for $\dot{Q}$ in $\mathrm{kW}$ and $H$ in meters, this implies an $f$ of 13 . This compares to a value of about 6.6 [7] for the isolated ceiling directly above the plume source $(r=0)$ beyond which the temperature drops due to entrainment of cold air into the ceiling jet. These findings together with figure 10 indicate that for a $H=2.3 \mathrm{~m}$ high room between 500 and $700 \mathrm{~kW}$ (depending on the plume character, i.e., whether the thermal discontinuity approaches the floor at $550{ }^{\circ} \mathrm{C}$ or $700{ }^{\circ} \mathrm{C}$ ) are required for a fully involved fire. However, flashover will occur at much smaller fire sizes not requiring $D$ to go completely to the floor. As an example, for flashover Lee [4] finds only about $475 \mathrm{~kW}$ are required for a fire in the center of a room of this size, with 400 and $340 \mathrm{~kW}$ for the wall and corner, respectively.

The adequacy of the two temperature hydraulics-orifice

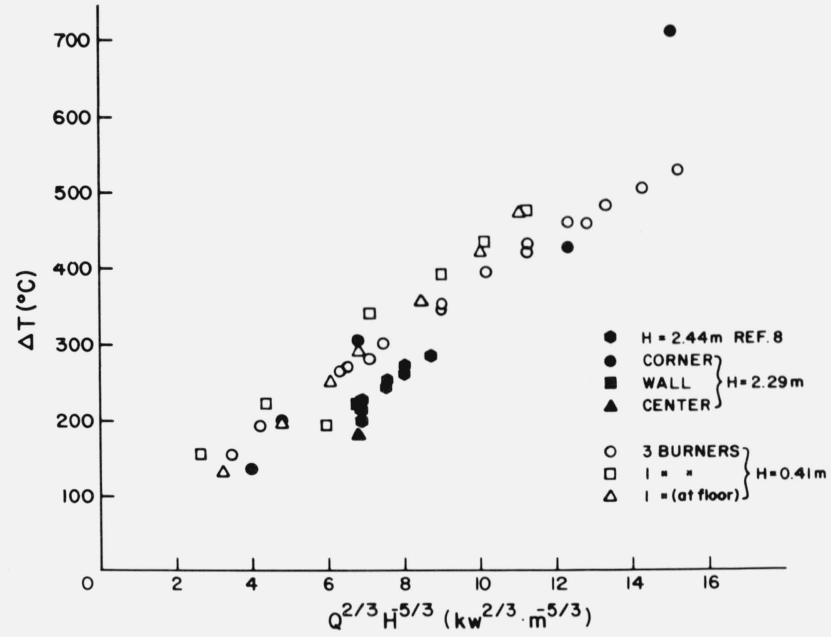

FIGURE 12. Upper gas temperature as a function of fire and compartment size.

enclosure flow model is illustrated in figure 13. The points represent the average flow into and out of the enclosure using equations 4 and 5 where $N$ and $D$ were determined directly from the ceiling and floor measurement of $\Delta p$ together with upper gas temperature. The abcissa is simply the thermal discontinuity normalized to opening height. The downward curving lines on figure 13 are the theoretical calculation for three absolute temperature ratios. They are derived from equation 4 plus another relation, that of continuity, $\dot{m}_{0}=\dot{m}_{i}$, which gives $N$ in terms of $D$ for various temperature ratios. For completeness it is presented here from reference [1]:

$$
\left(\frac{1-N / H_{0}}{N / H_{0}}\right)^{3}=(1-D / N)\left(1+\frac{D}{2 N}\right)^{2} \frac{T}{T_{0}} .
$$

Choosing a $D$ results in a fixed $N$ for a given $T$, and $N$ results in a unique flow rate from eq (4). The agreement between theory and experiment is good and figure 13 demonstrates both the consistency between the separate floor and ceiling pressure measurements as well as the adequacy of the simple enclosure flow model.

\subsection{Plume Entrainment}

The remaining piece of the enclosure fire picture concerns the fire plume. Cold air is swept through the door and is imagined to be heated in the plume and carried up from the lower to the upper portion of the room by entrainment into the plume from the base of the burner up to the thermal discontinuity, $D$. This amount of flow is equal to what is coming into the enclosure as well as what is leaving. Entraining of hot gases above $D$ does not contribute to the mass balance but rather it accounts for the recirculating flow responsible for the well stirred temperatures found in the upper portion of the room. The problem reduces to finding a relation involving the amount of entrainment and the height of the thermal discontinuity for a given fire such that its locus will intersect the enclosure flow at the appropriate flow and height, i.e., the points on figure 13 . 


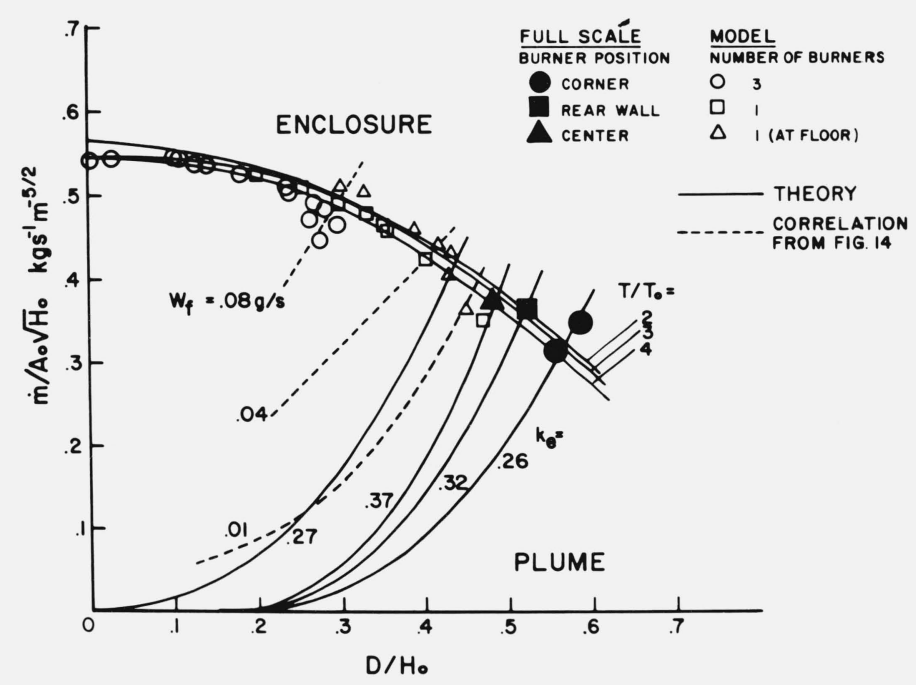

FIGURE 13. Enclosure mass flow rate as a function of thermal discontinuity height.

Several fire plume models exist; the one chosen here from reference [1] is an adaptation of work by Fang [9] and Stewart [10]. The total flow in the plume, $W_{p}$, is given as a function of the fuel injection rate, $W_{f}$; a fuel property, $\omega$; density ratio, ambient to fuel, $\rho_{0} / \rho_{f}$; plume entrainment coefficient, $k_{e}$, and finally, the height above the burner, $D$. Rockett's [1] eq (6) is

$$
\begin{aligned}
W_{p}=W_{f} \omega \frac{\rho_{0}}{\rho_{f}}\left(\left\{\frac{4}{5} k_{e}^{4 / 5}\left[\frac{5}{12} \frac{(1-\omega)}{\omega^{3}} \pi^{2} g \rho_{f}^{2}\right]^{1 / 5}\right.\right. \\
\left.\left.\left(\frac{D^{5 / 2}}{W_{f}}\right)^{2 / 5}+1\right\}^{5 / 2}-1\right)+W_{f}
\end{aligned}
$$

and

$$
\omega=\frac{M_{0 / f}}{M_{0}} /\left(1+\frac{\Delta H}{r C_{p} T_{0}}\right)
$$

where $M_{0 / f} / M_{0}$ is the ratio of the molecular weight of the flame gas to that of air; $\Delta H$ is the heat of combustion; $r$ is the air-fuel weight ratio and $C_{p}$ the specific heat. For methane $\omega=0.091$. Note that the entrained portion of the plume flow is a function of the entrainment constant to the second power, the thermal discontinuity to the two-and-onehalf power, and is practically independent of the initital fuel injection rate, $W_{\boldsymbol{f}}$. This latter result, typical of most plume analysis by their very nature will render the model incapable of reproducing all the data on figure 13 . For a given set of symbols on figure 13 the only parameter varied was the injection or burner gas flow rate, $W_{f}$. If a single entrainment coefficient is used for a given burner geometry the plume

3 J. Quintiere (of the Center for Fire Research, NBS) has recently verified the applicability of this approximate expression by solving the full equations of Stewart's Model. For a source with small this approximate expression by solving the full equations of Stewart's Model. For a source with small
momentum the results were virtually identical between eq (8) and the exact expression given by momentum the results were virtually identical characteristics will not span a wide enough range to cover the extremities of the data on figure 13 unless the plume varies with $W_{f}$ to a greater degree than given by the model.

Figure 14 contains the plume flow versus injection rate both normalized to $D^{5 / 2}$ for the theoretical model, i.e., eq (8), for three entrainment coefficients: $0.1,0.25$, and 0.4 shown by the solid lines. The data is obtained by taking the average mass flow rate through the enclosure and dividing

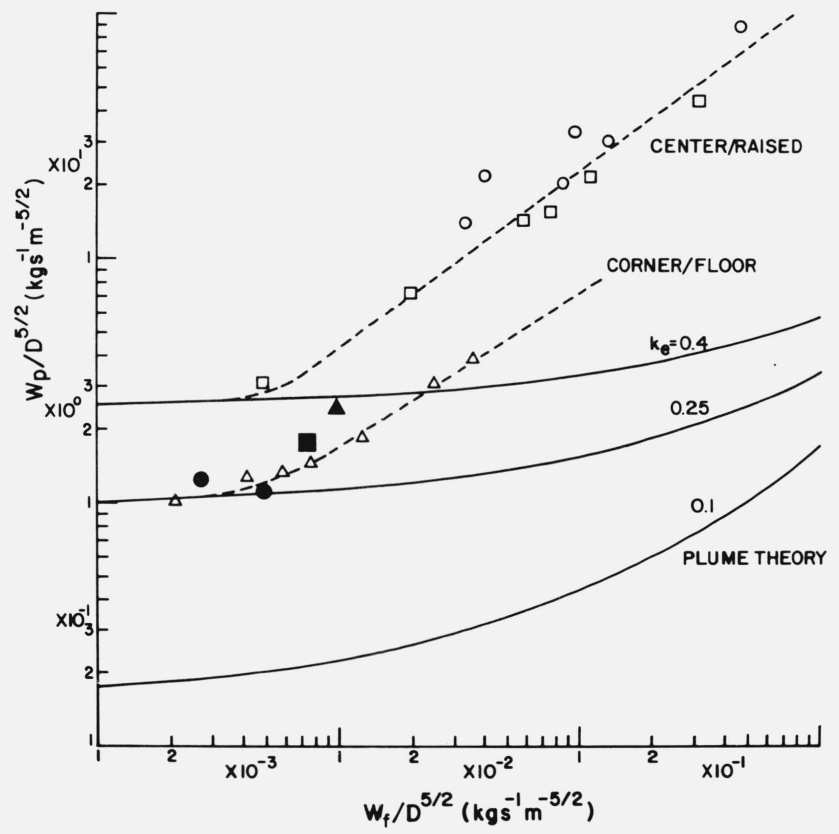

Figure 14. Plume entrained flow versus burner injection rate. 
by an effective entraining $D^{5 / 2}$, where $D$ is the determined thermal height in the enclosure minus the height of the burner off the floor. The abcissa is simply the measured $\mathrm{CH}_{4}$ flow rate through the burner divided by the same $D^{5 / 2}$. For the small scale three burner case (opened circles) the entrained flow and burner gas flow have been divided by three so as to give an average single burner characteristic. The problem with the plume model is evident in figure 14the weak dependence on burning rate of the model as against a strong dependence indicated by the data. The range of plume Froude number $\left(\mathrm{Fr}=u_{f}^{2} / g y_{0}\right.$ where $u_{f}$ is the gas velocity at the exit of the burner of radius $y_{0}$ ) runs from $2 \times 10^{-5}$ for the three burners above the floor case to $4 \times$ $10^{-1}$ for the single, smaller diameter burner located at the floor. The full-scale results are for Froude numbers of $2 \times$ $10^{-4}$ to $10^{-3}$.

The plume model using rather large entrainment coefficients can obviously be used for the full scale results since there is insufficient data to demonstrate the injection dependence. This is done in figure 13 and the resulting entrainment coefficients are 0.37 for the center burner, 0.32 for the wall and 0.26 for the corner configuration. Larger than "normal" entrainment rates for diffusion flames have been previously noted by Thomas [11] as well as Ricou and Spalding [12]. It could be expected that the differences between entrainment should go in the ratio of $1,3 / \mathbf{4}$, and $1 / 2$ for a square burner in that the wall limits $1 / 4$, and the corner $1 / 2$, of the flow. It is interesting and perhaps fortuitous that $(0.32 / 0.37)^{2}=$ 0.75 and $(0.26 / 0.37)^{2}=0.49$. Using the plume model for the case of the small scale burner at the floor (opened triangles) $k_{e}$ averages 0.27 for the lowest four points on figure 14 where the injection dependence is weak. (For this case the entraining height $D$ is equal to that measured from the floor.) For the raised burners in small scale the asymptotic, weak injection dependence result appears to yield entrainment coefficients of approximately 0.4 consistent with the raised, full-scale, center results. The data can probably be bracketed between the extremes of a raised, center burner and a corner or burner position at the floor shown by the dashed lines on figure 14. The lower result is included on figure 13 for three gas flow rates, in order to complete the enclosure plume model. Note that this discussion will not apply to those points whose determined $D$ falls below the height of the burner since any model of the plume assumes entrainment from the burner upwards to $D$. As $D$ gets smaller even before reaching the top of the burner the plume model representation will become poorer. It should be pointed out that this analysis is valid only within the framework of the two temperature model for the enclosure flow, i.e., entrainment above this "effective" $D$ is not contributing to flow in and out the door. However the enclosure portion of the work and the previous figures are independent of the plume and should therefore still be valid for $D$ approaching the floor.

From equation 8 two limiting conditions exist for high and low values of $W_{f} / D^{5 / 2}$. For low values of injection rates and large $\mathrm{D}$ the plume flow is independent of the injection rate, i.e., the left-hand horizontal portion of the curves representing the theory on figure 14. In this limit the entrained flow goes with $D^{5 / 2}$ (plume-like). For large injection rates and small $D$ the entrained flow is independent of $D$ and is equal to the burner flow to the first power, a $45^{\circ}$ line on the right side of figure 14 (jet-like). The present small scale data of a plume with combusion appears to fall between these plumejet limits with the transition considerably shifted to smaller
$W_{f} / D^{5 / 2}$. For a given $W_{f}$ on figure 13 the slope of the dashed lines will be increasing as $D$ gets larger indicating the transition from jet-like to plumelike behavior.

Once more, if the experimentally determined heights are used for the full-scale points, they are shifted slightly, but the conclusion remains: present plume models do not agree with the data.

\section{Conclusions and Recommendations}

The overall flow portion of the hydraulics-orifice enclosure model appears to be very consistent with the experimental observations. Additional full-scale measurements are suggested with emphasis on more extensive doorway velocity traversing. More accurate assessment of discharge coefficients could be determined; some of the other minor difficulties noted here might be resolved as well. How the neutral plane and thermal discontinuity vary with increasing fire size, position, and height of the burner must also be validated in full-scale. That would result in a clearer picture of the transient behavior of the enclosure fire and perhaps a more quantitative description of the factors leading to flashover.

The present results indicate that plume entrainment is not well enough understood. The strong dependence of the entrained flow on gas burner flow rate must be validated in full-scale. This result could have significant implications with respect to an increased burning rate as the room tends toward a flashover condition. The large entrainment coefficients derived from the data are probably an indication of the general lack of understanding of the precise physics and chemistry of turbulent diffusion flames. Until the effects of the simple gas burner are understood it will be very difficult to relate plume entrainment to enclosure flow during a real fire when upper gas, walls and ceiling are radiating to the unburned fuel array in a complex manner.

\section{References}

[1] Rockett, J. A., Fire induced gas flow in an enclosure, Combus. Sci. Technol., 12, 165 (1976).

[2] Quintiere, J. G., The Growth of Fire in Building Compartments, ASTM-NBS Symposium on Fire Standards and Safety, National Bureau of Standards, Gaithersburg, Md., April 5-6, 1976.

[3] Prahl, J., and Emmons, H. W., Fire Induced Flow Through An Opening, Combus. Flame. 25, 369 (1975). See also Zukowski, E. E. (report in preparation) Calif. Inst. of Technology, Pasadena, Calif.

[4] Lee, B. T., Quarter Scale Modeling of Room Fire Tests of Interior Finish, NBSIR in preparation.

[5] McCaffrey, B. J. and Quintiere, J. G., Fire Induced Corridor Flow in a Scale Model Study, CIB Symposium on the Control of Smoke Movement in Building Fires, Garston, U.K., November 4-5, 1975.

[6] Den Braven K. R., The Burning of Plexiglass Sheets in Small Enclosures, NBSIR in preparation.

[7] Heskestad, G., Physical Modeling of Fire, J. Fire Flammability. 6, 253 (1975)

[8] Tu, K. M., A Characterization and Analysis of NBS Furnishing Burn Room Experiments, NBSIR in preparation.

[9] Fang, J. B., Analysis of the behavior of a freely burning fire in a quiescent atmosphere, Nat. Bur. Stand. (U.S.), NBSIR 73-115 (Feb. 1973).

[10] Stewart, F. R., Prediction of the Height of Turbulent Diffusion Buoyant Flames, Comb. Sci. and Tech. 2, 203 (1970).

[11] Thomas, P. H., Baldwin R., and Heselden, A. J. M., Buoyant Diffusion Flames: Some Measurement of Air Entrainment, Heat Transfer and Flame Merging, Tenth Symposium (INT) on Combustion, The Combustion Institute, 983 (1965).

[12] Ricou, F. P., and Spalding, D. B., Measurement of entrainment by axisymmetrical turbulent jets, J. Fluid Mechanics 11, 21 (1961). 